\title{
Analisis Sensitivtas Pemodelan Matematika Epidemi Toksoplasmosis dengan Efek Vaksinasi
}

Meri Hari Yanni

STKIP Bumi Persada Lhokseumawe,merihyanni@gmail.com

\begin{abstract}
ABSTRAK, Analisis sensitivitas model epidemi toksoplasmosis dengan efek vaksinasi dilakukan untuk mengetahui pengaruh perubahan nilai parameter terhadap nilai basic reproduction number (Ro). hasil penelitian menunjukkan bahwa terdapat dua titik ekuilibrium yaitu titik ekuilibrium bebas penyakit dan titik ekuilibrium endemi. Hasil analisis sensitivitas menunjukan bahwa laju kelahiran yang terinfeksi toksoplasmosis dan Laju individu terinfeksi toksoplasmosis yang tervaksinasi merupakan parameter yang sangat berpengaruh terhadap basic reproduction number. Kondisi tersebut diperoleh Ketika dilakukan peningkatan pada laju kelahiran yang terinfeksi toksoplasmosis mengakibatkan basic reproduction number meningkat, begitupun sebaliknya. Sementara itu, ketika dilakukan peningkatan pada Laju individu terinfeksi toksoplasmosis yang tervaksinasi mengakibatkan basic reproduction number menurun. Hasil ini mengimplikasikan bahwa tingkat pemberian vaksin toksoplasmosis bagi individu yang terinfeksi memiliki pengaruh yang sangat besar dalam pengendalian penyakit toksoplasmosis d Banda Aceh.
\end{abstract}

Kata Kunci: Model Matematika, Analisis Sensitivitas, Toksoplasmosis

\section{PENDAHULUAN}

Banda Aceh merupakan ibu kota provinsi Aceh yang berada di Indonesia dengan pusat pemerintahan berada di kota Banda Aceh. Jumlah penduduk masyarakat Banda Aceh relatif banyak yaitu sebesar 244.689 pada tahun 2018 dengan kegiatan perekonomian berpusat di Banda Aceh. Berdasarkan kondisi letak geografis, Banda Aceh memiliki iklim tropis basah dengan tingkat kelembaban udara berada pada angka $70 \%$ hingga $80 \%$ sehingga menjadikan wilayah ini salah satu faktor berkembangnya penyakit toksoplasmosis.

Toksoplasmosis merupakan suatu penyakit menular pada manusia dan hewan yang disebabkan oleh parasit toksoplasma gondi dengan sumber utama perkembangannya melalui hewan felidae (Kucing) [1]. Kebiasaan masyarakat Banda Aceh dalam mengkonsumsi daging atau ayam yang dimasak kurang matang menjadikan salah satu potensi terinfeksinya toksoplasmosis, salah satunya adalah sate. Kebiasaan tersebut menimbulkan dampak yang berbahaya bagi masyarakat yang terinfeksi yaitu menyebabkan abortus, kematian dini pada janin, kelainan pada bayi dan dampak lainnya adalah gangguan neurolgis .

Saat ini, penanganan yang dapat diberikan kepada individu yang terinfeksi adalah dengan mengkonsumsi obat-obatan. Namun, pada kondisi dorman penyakit tidak dapat dikendalikan sehingga ketika system imun tubuh menurun mengakibatkan penyakit aktif kembali [2]. Pemberian obat toksoplasmosis diberikan hanya kepada individu yang telah diketahui terinfeksi toksoplasmosis, sedangkan bagi individu rentan pengobatan tidak dilakukan.

Para peneliti sedang mengembangan suatu vaksin toksoplasmosis bagi hewan, pemberian vaksin merupakan solusi yang paling efektif dan layak dalam membantu pencegahan penyebaran penyakit menular. Pemberian vaksin dilakukan untuk mencegah parasit masuk ke dalam tubuh manusia dan meningkatkan sistem kekebalan tubuh terhadap serangan penyakit.

Saat ini, Vaksin Toxovax ${ }^{\circledR}$ merupakan salah satu vaksin toksoplasmosis yang berlisensi yaitu live-attenuated T. gondii S48 [3]. Vaksin ini merupakan vaksin hidup untuk domba yang tersedia di belanda (Toxovax, intervet BV) dan di New Zealand (Toxovax,Agvax, dan Ag Research). Vaksin-vaksin tersebut telah mendapat lisensi untuk digunakan di UK, Irlandia, Perancis, Portugal, dan Spanyol. Penelitian di lapangan menunjukkan bahwa vaksin dari strain toxovax S48 dan T-263 T.gondii menyebabkan kontaminasi lingkungan oleh ookista menurun sehingga infeksi toksoplasma pada hewan mamalia menurun. Semua vaksin memberikan tingkat perlindungan pada kucing, namun masih dilakukan pengembangan dalam pembuatan vaksin rekombinan yang dapat digunakan pada manusia [4].

Efektivitas dalam pemberian vaksin toksoplasma pada manusia masih dalam suatu permasalahan kesehatan dalam transmisi penyakit. Hal tersebut dikarenakan dampak yang dapat terjadi masih dalam perhatian yang besar 
seperti tidak memberikan reaksi yang diinginkan oleh system kekebalan tubuh terhadap antigen yang diberikan oleh vaksin. Kurangnya respons system kekebalan tubuh disebabkan oleh beberapa faktor klinis seperti infeksi HIV, diabetes, penggunaan steroid dan usia. Dengan demikian, diperlukan suatu pemodelan atau pendekatan terhadap masalah yang dirumuskan dalam mengantisipasi efek-efek yang muncul pada program vaksinasi manusia pada epideiologi penyakit dalam jangka menengah dan panjang.

Sampai saat ini penelitian pemodelan matematika terkait penyebaran toksoplasmosis pada masyarakat Aceh masih sangat jarang dilakukan. Pada tahun 2010 angka prevalensi toksoplasmosis pada masyarakat di Banda Aceh sebesar 3,15\% [5]. Selanjutnya, Penelitian pemodelan matematika pengendalian epidemi toksoplasmosis pernah dilakukan di Kota Lhokseumawe dengan memperhatikan populasi terkontrol [6]. Kemudian dilakukan pengembangan terhadap analisis bifurkasi pengendalian epidemi toksoplasmosis di Kota Lhokseumawe dengan memperhatikan beberapa kondisi yang mempengaruhi penyebaran penyakit toksoplasmosis [7].

Tujuan dari penelitian ini adalah mengkonstruksi sebuah model matematika yang menggambarkan penyebaran toksoplasmosis dengan efek vaksinasi kepada masyarakat Banda Aceh dengan menggunakan Data dari Dinas Kesehatan Banda Aceh dan artikel-artikel pendukung lainnya. Analisis yang digunakan pada penelitian ini merupakan analisis sensitivitas dengan tujuan untuk mengetahui parameter-parameter yang berpengaruh terhadap epidemic penyakit toksoplasmosis dengan efek vaksinasi serta implikasi yang terjadi pada perubahan parameter terhadap bilangan reproduksi dasar (Ro).

\section{TINJAUANPUSTAKA}

\section{Toksoplasmosis}

Toksoplasmosis merupakan suatu penyakit menular pada manusia dan hewan yang disebabkan oleh parasit toksoplasma gondi dengan sumber utama perkembangannya adalah hewan felidae (Kucing). Penyebaran toksoplasmosis di lingkungan masyarakat dapat terjadi secara vertikal maupun horizontal. Penyebaran vertikal terjadi melalui ibu kepada anak sedangkan horizontal melalui kontak langsung dengan media penyebaran di lngkungan serta memakan makanan yang dimasak kurang matang. Penyebaran penyakit memberikan dampak yang sangat berbahaya bagi wanita hamil seperti abortus, kelainan pada janin hingga kematian janin .

\section{Sistem Persamaan Diferensial Biasa Non Linier}

Bentuk umum dari persamaan diferensial biasa non linier.

$$
\begin{gathered}
a_{0}(t) \frac{d^{n} x}{d t^{n}}+a_{1}(t) \frac{d x}{d t}+\cdots+a_{n-1}(t) \frac{d^{n-1} x}{d t^{n-1}}+a_{n}(t) x=f(t) \\
\text { Dengan } \quad a_{n} \neq 0, a_{0}, a_{1}, \ldots, a_{n-1}, a_{n}
\end{gathered}
$$
disebut koefisien persamaan diferensial. Fungsi $\mathrm{f}(\mathrm{t})$ disebut input dan solusi dari persamaan diferensial $\mathrm{x}(\mathrm{t})$ disebut output. Jika ruas kanan $\mathrm{f}(\mathrm{t})$ bernilai 0 untuk semua nilai $\mathrm{t}$ dalam interval yang ditinjau, maka persamaan ini disebut homogen, jika sebaliknya disebut nonhomogen.

Misal suatu persamaan diferensial biasa dinyatakan sebagai berikut:

$$
\dot{x}=\frac{d x}{d t} A x+b ; \mathrm{x}(0)=a_{0} \in \mathbb{R}^{n}
$$

Dengan A merupakan matriks koefisien konstan berukuran nxn dan $\mathrm{b}$ adalah vector konstan. Sistem persamaan (5) disebut Sistem Persamaan Diferensial Biasa Linier Orde Satu dengan kondisi awal $\mathrm{x}(0)=x_{0}$. Apabila $\mathrm{b}=0$ maka system disebut homogen dan jika $b \neq 0$ maka system disebut non homogeny.

Misal suatu sistem persamaan diferensial

biasa dinyatakan dalam persamaan berikut

$$
\dot{x}=f(x, t)
$$

dengan

$$
x=\left[\begin{array}{c}
x_{1}(t) \\
x_{2}(t) \\
\vdots \\
x_{n}(t)
\end{array}\right] \text { dan } f(x, t)=\left[\begin{array}{c}
f_{1}\left(t, x_{1}, x_{2}, \ldots, x_{n}\right) \\
f_{2}\left(t, x_{1}, x_{2}, \ldots, x_{n}\right) \\
\vdots \\
f_{n}\left(t, x_{1}, x_{2}, \ldots, x_{n}\right)
\end{array}\right]
$$


Merupakan fungsi nonlinier dalam $x_{1}, x_{2}, \ldots, x_{n}$. Sistem persamaan (6) disebut system persamaan diferensial nonlinier.

\section{Titik Tetap Ekuilibrium}

Definisi 2.1 Titik $\hat{\boldsymbol{x}} \in \mathbb{R}^{\boldsymbol{n}}$ disebut titik ekuilibrium Sistem Persamaan (6) jika $\boldsymbol{f}(\hat{\boldsymbol{x}})=$ $\mathbf{0}$ [8].

Terdapat dua titik Ekuilibrium yaitu

1. Titik ekulibrium bebas penyakit yaitu

2. keadaan dimana tidak terjadinya penyebaran penyakit menular dalam suatu populasi

3. Titik ekuilibrium endemic yaitu keadaan dimana terjadinya penyebaran penyakit menular dalam suatu populasi

\section{Bilangan Reproduksi Dasar $\boldsymbol{R}_{\mathbf{0}}$}

Bilangan reproduksi dasar merupakan rata-rata banyaknya infeksi sekunder yang dihasilkan oleh satu individu terinfeksi dalam suatu populasi rentan [9]. Dalam menentukan $R_{0}$ terlebih dahulu mengasumsikan suatu model epidemic yang dituliskan ke dalam bentuk

$$
\begin{aligned}
\frac{d X}{d t}=f(X, Y, Z) & \\
& \frac{d Y}{d t}=g(X, Y, Z)
\end{aligned}
$$

$$
\frac{d Z}{d t}=h(X, Y, Z)
$$

Vektor X menyatakan subpopulasi yang tidak terinfeksi, $\mathrm{Y}$ menyatakan subpopulasi yang terinfeksi dan laten, $\mathrm{Z}$ menyatakan vector subpopulasi terinfeksi dan menularkan. Selanjutnya, menentukan titik ekuilibrium bebas penyakit $\left(X^{*}, 0,0\right)$. Selanjutnya, mendefinisikan $A:=$ $\frac{\partial}{\partial Z} h\left(X^{*}, \hat{g}\left(X^{*}, 0\right), 0\right)$. Kemudian menentukan $\mathrm{M}$ dan $\mathrm{D}$ sehingga $\mathrm{A}=\mathrm{M}-\mathrm{D}, \mathrm{M} \geq 0, D \geq 0$ (diagonal). Matriks $\mathrm{D}$ dicari inversnya sehingga diperoleh $D^{-1}$ yang merupakan non negative. Dengan demikian, $\mathrm{M} D^{-1}$ merupakan Bilangan reproduksi dasar $\left(R_{0}\right)$.

\section{Analisis Sensitivitas}

Anlisis sensitivitas merupakan suatu analisis yang dilakukan untuk mengetahui parameter-parameter yang berpengaruh pada model matematika terhadap laju perubahan model.
Analisis sensitivitas dilakukan dengan menghitung nilai indeks sensitivitas dari parameter tersebut.

Definisi 2.2 Normalized Sensitivity index diperoleh dengan indeks sensitivitas normalisasi dari variable $V$, terdiferensialkan pada parameter $p$, didefinisikan sebagai berikut:

$$
C_{p}^{V}=\frac{\partial V}{\partial p} \times \frac{p}{V}
$$

dimana $\mathrm{V}$ adalah variable yang akan dianalisis dan $\mathrm{p}$ adalah parameter [10].

Definisi diatas menunjukkan bahwa indeks sensitivitas dicari dengan menggunakan konsep laju perubahan yang kemudian diukur besar kecilnya perubahan tersebut. Semakin besar indeks tersebut maka semakin besar pengaruh parameter tersebut terhadap variabel yang diukur. Perlu dipahami kembali bahwa jika nilai indeks sensitivitas bernilai positif dan negative maka menunjukkan hubungan antara parameter tersebut dengan variable.

\section{METODOLOGI PENELITIAN}

Penelitian dilakukan di Kota Banda Aceh. Data yang digunakan dalam penelitian adalah data sekunder tentang penyakit toksoplasmosis dan berdasarkan hasil wawancara dengan tim medis dokter spesialis kandungan. Beberapa data yang digunakan pada penelitian diperoleh dari Dinas Kesehatan Kota Banda Aceh pada Tahun 2018 dan beberapa data lainnya diperoleh dari estimasi parameter penelitian pendukung lainnya.

\section{Prosedur Penelitian}

Tahapan-tahapan yang dilakukan dalam penelitian ini adalah sebagai berikut

1. Meninjau masalah yang dihadapi dengan data medis maupun literature pendukung

2. Dilakukan penyusunan kriteria penelitian yang diuji dan dilakukan revisi melalui interview serta wawancara kepada narasumber ahli yaitu dokter spesialis kandungan.

3. Mengkonstruksi model matematika

4. Menentukan Titik ekuilibrum model

5. Menentukan bilangan reproduksi dasar (Ro)

6. Melakukan analisis sensitivitas model dan implikasi dari analisis yang diperoleh 
7. Menarik Kesimpulan.

\section{HASIL DAN PEMBAHASAN}

\section{Formulasi model epidemi toksoplasmosis dengan efek vaksinasi}

Model matematika epidemi

toksoplasmosis ini merupakan pengembangan pada model epidemi toksoplasmosis yang dipaparkan oleh Yanni dengan penambahan pada efek vaksinasi. Penambahan efek vaksinasi dilakukan berdasarkan perkembangan medis dalam mengembangkan suatu vaksin Toksoplasmosis yang telah diujicoba pada hewan domba (mamalia).

Pada penyebaran penyakit toksoplasmosis, populasi manusia dapat diklasifikasikan menjadi 4 populasi yaitu populasi yang rentan dinotasikan dengan $\mathrm{S}$, populasi yang terinfeksi dinotasikan dengan I, populasi terkontrol terhadap penyakit toksoplasmosis dinotasikan dengan $\mathrm{C}$, dengan jumlah populasi tervaksin toksoplasmosis dinotasikan dengan V. Asumsi yang digunakan pada penelitian adalah vaksin diberikan kepada individu rentan dan individu yang terinfeksi toksoplasmosis, perlakuan pada individu terkontrol diasumsikan berbeda dengan individu tervaksinasi, Pada Individu rentan diasumsikan secara umum sama yaitu tidak mengkategorikan antara individu dengan sistem imun menurun, individu yang sedang hamil, maupun individu dewasa (sistem imun baik). Berdasarkan faktafakta dan asumsi-asumsi di atas, model penyebaran epidemi toksoplasmosis dengan efek vaksinasi diberikan oleh persamaan :

$$
\begin{aligned}
& \frac{d S}{d t}=\delta-\alpha S I-\beta S-\mu S+\theta C \\
& \frac{d I}{d t}=\alpha S I+\sigma I-\Omega I-(\mu+d) I-\varepsilon I \\
& \frac{d C}{d t}=\varepsilon I-\theta C-\mu C \\
& \frac{d V}{d t}=\Omega I+\beta S-\mu V
\end{aligned}
$$

dengan:

$\delta=$ laju kelahiran

$\theta=$ laju individu terkontrol menjadi individu rentan

$\alpha=$ laju infeksi Toksoplasmosis

$\mu=$ laju kematian alami $d=$ laju kematian yang disebabkan Toksoplasmosis

$\varepsilon=$ laju individu yang terkontrol

$\sigma=$ laju kelahiran yang telah terinfeksi toksoplasma

$\beta=$ Laju individu rentan yang tervaksinasi

$\Omega=$ Laju individu terinfeksi toksoplasmosis yang tervaksinasi

Setiap parameter bernilai positif dan kondisi awal dari setiap variabel adalah positif, $S(0) \geq 0, I(0) \geq 0$, dan $C(0) \geq 0$.

\section{Titik ekuilibrium model}

Titik ekuilibrium pada sistem (1)-(4) diperoleh dengan menyelesaikan persamaan $\frac{d S}{d t}=\frac{d I}{d t}=\frac{d C}{d t}=0$.

Pada sistem persamaan (2) diperoleh $\alpha S I+\sigma I-\Omega I-(\mu+d) I-\varepsilon I=0$

$\Leftrightarrow I=0 \quad \vee \quad S=\frac{\Omega+\varepsilon+\mu+d-\sigma}{\alpha}$

Kasus $I=0$;

Pada sistem persamaan (3) untuk kasus $I=0$ diperoleh

$\varepsilon I-\theta C-\mu C=0 \Leftrightarrow C=\frac{\varepsilon}{\theta+\mu} I$,

karena $I=0$ maka diperoleh $\mathrm{C}=0$. Selanjutnya, pada sistem persamaan (1) untuk kasus $I=0$ dengan mensubtitusikan $\mathrm{C}=0$ maka diperoleh $\delta-\alpha S I-\beta S-\mu S+\theta C=0$

$$
\Leftrightarrow S=\frac{\delta}{\beta+\mu}
$$

Kemudian, subtitusikan persamaan (7) ke persamaan (4) untuk kasus $I=0$ diperoleh

$\Omega I+\beta S-\mu V=0$

$$
\Leftrightarrow V=\frac{\beta \delta}{\mu(\beta+\mu)}
$$

Dengan demikian diperoleh titik ekuilibirum bebas penyakit toksoplasmosis yaitu

$E_{o}=\left(\frac{\delta}{\beta+\mu}, 0,0, \frac{\beta \delta}{\mu(\beta+\mu)}\right)$.

Kasus $I \neq 0$;

Selanjutnya, akan ditentukan titik ekuilibirum endemik dengan mengasumsikan $I \neq 0$. Dari persamaan kedua pada persamaan (5) diperoleh

$$
S=\frac{\Omega+\varepsilon+\mu+d-\sigma}{\alpha}
$$


Kemudian, pada persamaan (9) dan persamaan (6) di subtitusikan ke persamaan (1) sehingga diperoleh

$I=\frac{(\mu+\theta)[\alpha \delta-(\beta+\mu)(\Omega+\varepsilon+\mu+d-\sigma)]}{\alpha[(\mu+\theta)(\Omega+\mu+d-\sigma)+\mu \varepsilon]}$

Selanjutnya persamaan

disubtitusikan ke persamaan (6), diperoleh

$C=\frac{\varepsilon[\alpha \delta-(\beta+\mu)(\Omega+\varepsilon+\mu+d-\sigma)]}{\alpha[(\mu+\theta)(\Omega+\mu+d-\sigma)+\mu \varepsilon]}$.

Lebih lanjut, pada persamaan (9) dan persamaan (11) disubtitusikan ke persamaan (4) sehingga diperoleh

$V^{*}=\frac{\beta(\Omega+\varepsilon+\mu+d-\sigma)(\theta[(\mu+\theta)(\Omega+\mu+d-\sigma)+\mu \varepsilon])}{\mu \alpha[(\mu+\theta)(\Omega+\mu+d-\sigma)+\mu \varepsilon]}$

Dengan demikian diperoleh titik ekuilibirum penyebaran penyakit toksoplasmosis dengan efek vaksinasi yaitu $E_{1}=\left(S^{*}, I^{*}, C^{*}, V^{*}\right)$ dengan

$S^{*}=\frac{\Omega+\varepsilon+\mu+d-\sigma}{\alpha}$

$I^{*}=\frac{(\mu+\theta)[\alpha \delta-(\beta+\mu)(\Omega+\varepsilon+\mu+d-\sigma)]}{\alpha[(\mu+\theta)(\Omega+\mu+d-\sigma)+\mu \varepsilon]}$

$C^{*}=\frac{\varepsilon[\alpha \delta-(\beta+\mu)(\Omega+\varepsilon+\mu+d-\sigma)]}{\alpha[(\mu+\theta)(\Omega+\mu+d-\sigma)+\mu \varepsilon]}$.

$[\alpha \delta-(\beta+\mu)(\Omega+\varepsilon+\mu+d-\sigma)] \Omega(\mu+\theta)+$

$V^{*}=\frac{\beta(\Omega+\varepsilon+\mu+d-\sigma)(\theta[(\mu+\theta)(\Omega+\mu+d-\sigma)+\mu \varepsilon])}{\mu \alpha[(\mu+\theta)(\Omega+\mu+d-\sigma)+\mu \varepsilon]}$

\section{Bilangan Reproduksi Dasar}

Untuk memperoleh bilangan reproduksi dasar maka terlebih dahulu dilakukan pengelompokan subpopulasi dari persamaan (1)

- (3) menjadi kompartemen X,Y, dan Z.

$X=\left[\begin{array}{l}S \\ C \\ V\end{array}\right], Y=0, Z=[I]$

sehingga dibentuk model kompartemen

$$
\begin{gathered}
\frac{d X}{d t}=\left[\begin{array}{c}
\delta-\alpha S I-\beta S-\mu S+\theta C \\
\varepsilon I-\theta C-\mu C \\
\Omega I+\beta S-\mu V
\end{array}\right]=f(X, Y, Z) \\
\frac{d Y}{d t}=0=g(X, Y, Z) \\
\frac{d Z}{d t}=[\alpha S I+\sigma I-\Omega I-(\mu+d) I-\varepsilon I] \\
=k(X, Y, Z)
\end{gathered}
$$

Kemudian fungsi $k(X, Y, Z)$ diturunkan terhadap I,sehingga diperoleh: $\frac{\partial k}{d t}\left(X^{*}, g\left(X^{*}, Z\right), Z\right)=\alpha S-\Omega-\varepsilon-\mu-d+\sigma$

)

Titik kesetimbangan bebas penyakit

$$
q_{o}=\left(\frac{\delta}{\beta+\mu}, 0,0, \frac{\beta \delta}{\mu(\beta+\mu)}\right),
$$

sehingga persamaan (4) menjadi

$$
\begin{aligned}
A & =\alpha \frac{\delta}{\beta+\mu}-\Omega-\varepsilon-\mu-d+\sigma \\
& =\left(\frac{\alpha \delta}{\beta+\mu}+\sigma\right)-(\Omega+\varepsilon+\mu+d)
\end{aligned}
$$

Bilangan reproduksi dasar $R_{o}=M D^{-1}$, dengan $M=\frac{\alpha \delta}{\beta+\mu}+\sigma$ dan $D=\Omega+\varepsilon+\mu+d$, sehingga diperoleh

$$
R_{o}=\frac{\alpha \delta+\sigma(\beta+\mu)}{(\beta+\mu)(\Omega+\varepsilon+\mu+d)}
$$

\section{Analisis Sensitivitas}

\begin{tabular}{|c|c|}
\hline Parameter & Nilai \\
\hline$\alpha$ & 0,008067 \\
\hline$\beta$ & 0,75 \\
\hline$\xi$ & 0,00833 \\
\hline$\Omega$ & 0,0667 \\
\hline$\sigma$ & 0,09 \\
\hline$\mu$ & 0,000426 \\
\hline d & 0,0146 \\
\hline$\delta$ & 0,000004087 \\
\hline$\theta$ & 0,0001 \\
\hline
\end{tabular}

Pada Model matematika pengendalian epidemic tosoplasmosis, analisis Indeks sensitivitas dilakukan pada Basic reproduction number $R 0$. Nilai parameter yang digunakan untuk perhitungan indeks sensitivitas merujuk pada Tabel 1 ketika $R_{0}>1$.

Tabel 1 Nilai parameter model matematika

Untuk bilangan $\quad R_{o}=\frac{\alpha \delta+\sigma(\beta+\mu)}{(\beta+\mu)(\Omega+\varepsilon+\mu+d)}$ terdapat empat parameter yang akan dicari indeks sensitivitasnya yaitu $\beta, \alpha, \Omega$ dan $\sigma>0$. Indeks sensitivitas dari parameter $\alpha$ adalah

$$
\begin{aligned}
& C_{\alpha}^{R_{o}}=\frac{\partial R_{o}}{\partial \alpha} \times \frac{\alpha}{R_{o}} \\
&=\frac{\delta}{(\beta+\mu)(\Omega+\varepsilon+\mu+d)} \\
& \quad \times \frac{\alpha(\beta+\mu)(\Omega+\varepsilon+\mu+d)}{\alpha \delta+\sigma(\beta+\mu)}
\end{aligned}
$$




$$
=\frac{\delta \alpha}{\alpha \delta+\sigma(\beta+\mu)}
$$

Dengan prosedur yang sama diperoleh ekspresi sensitivitas untuk parameter lainnya yaitu

- Indeks sensitivitas dari parameter $\sigma$ adalah

$$
\frac{\sigma(\beta+\mu)}{\alpha \delta+\sigma(\beta+\mu)}
$$

- Indeks sensitivitas dari parameter $\beta$ adalah

$$
\frac{\beta \sigma(\beta+\mu)-\beta(\alpha \delta+\sigma(\beta+\mu))}{(\beta+\mu)(\alpha \delta+\sigma(\beta+\mu))}
$$

- Indeks sensitivitas dari parameter $\Omega$ adalah

$$
\frac{-\Omega}{(\Omega+\varepsilon+\mu+d)(\alpha \delta+\sigma(\beta+\mu))}
$$

Nilai Hasil analisis indeks sensitivitas parameter dari basic reproduction number $R 0$ terhadap parameter pada model matematika epidemic toksoplasmosis dengan efek vaksinasi diberikan

\begin{tabular}{|c|c|c|c|}
\hline \multirow{2}{*}{$\begin{array}{l}\text { Para } \\
\text { meter }\end{array}$} & \multirow{2}{*}{$\begin{array}{c}\text { ekspresi } \\
\text { sensitivitas } \\
\text { Ro }\end{array}$} & \multicolumn{2}{|c|}{$\mathrm{Ro}=1,0010876$} \\
\hline & & $\mathrm{P}+5 \%$ & P-5\% \\
\hline$\alpha$ & 0,0000004882 & 99 & 0, \\
\hline & & & \\
\hline$\beta$ & & 0,9993453 & 0,999 \\
\hline & & & \\
\hline
\end{tabular}
pada Tabel 2 berikut.

Tabel 2. Ekspresi Sensitivitas Parameter Terhadap Basic Reproduction Number

Berdasarkan Tabel 2 diperoleh bahwa

a. Indeks sensitivitas untuk nilai parameter $\alpha$ adalah 0,0000004882, artinya apabila laju kontak antara populasi rentan dengan populasi terinfeksi bertambah sebesar 5\% mengakibatkan nilai $R 0$ menurun yang awalnya 1,001087603 menjadi 0,99934839. Begitupun juga jika nilai parameter $\alpha$ dikurang 5\% maka nilai $R 0$ menurun.

b. Indeks sensitivitas untuk nilai parameter $\sigma$ adalah 0,999999512, artinya apabila laju kelahiran yang telah terinfeksi toksoplasma bertambah sebesar 5\% mengakibatkan nilai $R 0$ naik menjadi 1,554536958. Namun sebaliknya, jika nilai parameter $\sigma$ dikurang $5 \%$ maka nilai $R 0$ menurun menjadi 0,444153765 . c. Indeks sensitivitas untuk $\beta$ adalah $-4,87887 \mathrm{E}-$ 07, artinya apabila Laju individu rentan yang tervaksinasi terinfeksi bertambah sebesar 5\% mengakibatkan nilai $R 0$ menurun menjadi 0,999345331 . Begitupun juga jika nilai parameter $\beta$ dikurang $5 \%$ maka nilai $R 0$ juga menurun.

d. Indeks sensitivitas untuk $\Omega$ adalah 10,96599692, artinya apabila Laju individu terinfeksi toksoplasmosis yang tervaksinasi bertambah sebesar 5\% mengakibatkan nilai $R 0$ menurun menjadi 0,642586652302. Namun sebaliknya, jika nilai parameter $\Omega$ dikurang $5 \%$ maka nilai $R 0$ naik menjadi 2,246687235 .

Berdasarkan penjelasan diatas diperoleh bahwa parameter pada model yang paling berpengaruh terhadap Basic Reproduction Number $\left(\mathrm{R}_{0}\right)$ adalah laju kelahiran yang telah terinfeksi toksoplasma $(\sigma)$ dan Laju individu terinfeksi toksoplasmosis yang tervaksinasi $(\Omega)$. Parameter $\sigma$ memiliki hubungan yang negative dan parameter $\Omega$ memiliki hubungan yang positif. Hal tersebut berarti bahwa ketika nilai parameter $\sigma$ meningkat maka jumlah individu yang terinfeksi toksoplasma meningkat yang berarti terjadinya epidemi penyakit toksoplasma di lingkungan masyarakat di Banda Aceh, dan begitu pun sebaliknya. Selanjutnya, ketika nilai parameter $\Omega$ meningkat maka jumlah individu terinfeksi toksoplasma yang tervaksinasi menurun akibatnya jumlah populasi yang terinfeksi semakin lama akan menurun sehingga penyakit toksoplasmosis dapat hilang dari populasi dan tidak adanya penyebaran penyakit toksoplasmosis di lingkungan masyarakat. Dengan demikian, pemberian vaksin toksoplasmosis bagi individu yang terinfeksi sangat mempengaruhi penyebaran penyakit sehinggat penyakit dapat teratasi lebih awal.

\section{KESIMPULAN}

Berdasarkan hasil yang $\begin{array}{r}\text { diperoleh, } \\ \text { epidemic }\end{array}$
pemodelan matematika
toksoplasmosis dengan efek vaksinasi
mempunyai dua titik ekuilibrium, yaitu titik
ekuilibrium bebas penyakit toksoplasmosis $E_{o}=$
$\left(\frac{\delta}{\beta+\mu}, 0,0, \frac{\beta \delta}{\mu(\beta+\mu)}\right)$ dan titik ekuilibirum


penyebaran penyakit toksoplasmosis dengan efek vaksinasi yaitu $E_{1}=\left(S^{*}, I^{*}, C^{*}, V^{*}\right)$ dengan

$$
\begin{gathered}
S^{*}=\frac{\Omega+\varepsilon+\mu+d-\sigma}{\alpha} \\
I^{*}=\frac{(\mu+\theta)[\alpha \delta-(\beta+\mu)(\Omega+\varepsilon+\mu+d-\sigma)]}{\alpha[(\mu+\theta)(\Omega+\mu+d-\sigma)+\mu \varepsilon]} \\
C^{*}=\frac{\varepsilon[\alpha \delta-(\beta+\mu)(\Omega+\varepsilon+\mu+d-\sigma)]}{\alpha[(\mu+\theta)(\Omega+\mu+d-\sigma)+\mu \varepsilon]} . \\
V^{*}=\frac{\beta(\alpha \delta-(\beta+\mu)(\Omega+d-\sigma)(\theta[(\mu+\theta)(\Omega+d)] \Omega(\mu+\theta)+d-\sigma)+\mu \varepsilon])}{\mu \alpha[(\mu+\theta)(\Omega+\mu+d-\sigma)+\mu \varepsilon]} .
\end{gathered}
$$

Bilangan reproduksi dasar pada model matematika diperoleh $R_{o}=\frac{\alpha \delta+\sigma(\beta+\mu)}{(\beta+\mu)(\Omega+\varepsilon+\mu+d)}$. Berdasarkan dari hasil analisis sensitivitas parameter model matematika toksoplasmosis diperoleh laju kelahiran yang telah terinfeksi toksoplasma $(\sigma)$ dan Laju individu terinfeksi toksoplasmosis yang tervaksinasi $(\Omega)$. Parameter tersebut merupakan parameter yang paling berpengaruh terhadap Basic Reproduction Number (Ro). Hasil ini mengimplikasikan bahwa tingkat pemberian vaksin toksoplasmosis bagi individu yang terinfeksi memiliki pengaruh yang sangat besar dalam pengendalian penyakit toksoplasmosis d Banda Aceh sehingga penyakit dapat teratasi lebih awal.

\section{DAFTAR PUSTAKA}

[1] Dubay, J.P, Toxoplasmosis of animals and Humans 2rd edition, Crc Press, Taylor and Francis Group, 2010.

[2] Robert F-G and Dardc M-L, Epidemiology of and Diagnostic Strategies for Toxoplasmosis, America Society for Microbiology 2014.

[3] Zhang, Nian-Zhang, Jia Chen, Meng Wang, Eskild Petersen, and Xing-Quan Zhu, Vaccines against Toxoplasma gondii : New developments and perspectives,Expert Review, University of Southern California, 2013.

[4] Innes, Elisabeth A, Clare Hamilton, Joao L. Garcia, Andreas Chryssafidis, and David Smith, A one health approach to vaccines against Toxoplasma gondii. Elsevier, 2019.

[5] Hanafiah, M., Kamaruddin, M., Nurcahyo, W., \&Winaruddin, Studi Infeksi Toksoplasmosis pada Manusia dan
Hubungannya dengan Hewan di Banda Aceh, Jurnal Kedokteran Hewan, 2010.

[6] Yanni, MH., Zulfahmi, Analisis Pemodelan dan Simulasi Matematika Pengendalian Epidemi Toksoplasmosis. Jurnal Teori dan Aplikasi Matematika (JTAM), 2019.

[7] Yanni, MH., Zulfahmi, Bifurcation Analysis of Toxoplasmosis Epidemic Control on Increased Controlled rate of suppressing the rate of infected births. Internatioanal Journal of Computing Science and Applied Mathematics (IJCSAM), 2020.

[8] Perko,L., Differential Equations and Dynamical System $3^{\text {rd }}$ Edition, Text in Applied Mathematics, New York: Springerverlage, 2001.

[9] Ma, Z., and Li, J., Dynamical Modeling and Analysis of Epidemics, Singapore: World Scientific Publishing, 2009.

[10] N . Chitnis, J.M. Hyman, and J.M. Cushing, Determining important parameters in the spread of malaria through the sensitivity analysis of a mathematical model, Bulletin of Mathematical Biology, 2008, 